\title{
Cipango
}

Cipango Cahiers d'études japonaises

\section{Le trousseau à Nagoya : réévaluer l'importance de la dot dans le Japon du $\mathrm{xx}^{\mathrm{e}}$ siècle}

Signification du trousseau

The Economic Aspect of Marriage in Japan: the Importance of the Trousseau in the Nagoya Area

\section{Garance Ducros}

\section{(2) OpenEdition \\ Journals}

\section{Édition électronique}

URL : https://journals.openedition.org/cipango/4077

DOI : $10.4000 /$ cipango.4077

ISSN : 2260-7706

\section{Éditeur}

INALCO

Édition imprimée

Date de publication : 1 juillet 2020

ISBN : 9782858313426

ISSN : 1164-5857

Référence électronique

Garance Ducros, «Le trousseau à Nagoya : réévaluer l'importance de la dot dans le Japon

du xxe siècle », Cipango [En ligne], 23 | 2020, mis en ligne le 16 juin 2020, consulté le 30 juin 2021. URL

http://journals.openedition.org/cipango/4077 ; DOI : https://doi.org/10.4000/cipango.4077

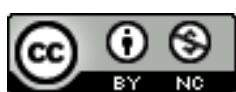

Cipango est mis à disposition selon les termes de la Licence Creative Commons Attribution - Pas d'Utilisation Commerciale 4.0 International. 


\title{
Le trousseau à Nagoya : réévaluer l'importance de la dot dans le Japon du $\mathbf{X x}^{\mathrm{e}}$ siècle Signification du trousseau
}

\author{
The Economic Aspect of Marriage in Japan: the \\ Importance of the Trousseau in the Nagoya Area
}

Garance Ducros

Chercheuse associée à la Maison franco-japonaise et au LISST

Dans les Structures élémentaires de la parenté, Claude Lévi-Strauss écrivait que le cadeau le plus important dans le mariage était la femme elle-même. Certes, mais le mariage est aussi l'occasion de divers échanges économiques. Selon l'Anthropologie de la famille et de la parenté, la terminologie anglo-saxonne serait plus explicite pour décrire les transactions engendrées par le mariage puisqu'elle opérerait une distinction entre les termes de dowry et de brideprice ou bridewealth. Le premier de ces mots que l'on peut traduire par dot « désigne le paiement effectué lors d'un mariage par les parents de la jeune fille ${ }^{1} \gg$, tandis que le second, le prix de la fiancée, caractérise « la pratique selon laquelle les parents d'un garçon doivent donner une compensation matrimoniale aux parents de la jeune fille ${ }^{2}$.»

1. DeliÈge, 2009 [1996], p. 13.

2. Ibid., p. 13. 


\section{CIPANGO \\ 298 Cahiers d'études japonaises n²3}

Dans leur ouvrage Bridewealth and Dowry, Jack Goody et S. J. Tambiah expliquent que la dot se rencontrerait essentiellement dans les sociétés européennes et asiatiques, là où la terre peut être possédée individuellement et où elle peut être exploitée de manière intensive. Ces deux conditions permettent en effet d'engranger des surplus à l'origine de la forte stratification sociale qui se rencontre dans ces sociétés.

On s'attend à trouver ce type de disposition au Japon. Pourtant, dans l' Histoire de la famille, Patrick Beillevaire rappelle qu'au Japon le mariage «par prise de la bru » qui supposait que la femme quitte sa famille pour aller s'installer chez son époux ne devint la norme qu'aux environs du $\mathrm{Xv}^{\mathrm{e}}$ siècle. Il indique toutefois, dans une partie sur la condition des femmes à l'époque antique et au Moyen Âge, que « de tous temps la notion de dot proprement dite est demeurée étrangère au système familial japonais ${ }^{3}$. » Il explique aussi un peu plus loin, à propos des mariages à l'époque d'Edo, que si « les considérations économiques n'étaient pas absentes du mariage au Japon ${ }^{4} »$, « les transferts de biens auxquels il donnait lieu [n'avaient] cependant jamais été très importants et revêtaient plutôt un caractère symbolique 5 . » François et Mieko Macé abondent dans ce sens dans leur ouvrage sur le Japon d'Edo où on peut lire que « le mariage n'était guère accompagné de prestation financière significative » et que « le Japon a ignoré l'institution de la dot » même si les auteurs concèdent que les jeunes filles se devaient d'apporter des « vêtements dans des armoires qui étaient transportées aux yeux de tous ${ }^{6}$. 》

Les vêtements et les armoires dont il est question ici correspondent aux yomeiri doggu 嫁入り道具, terme qui recouvre ce que l'on appelle le «trousseau » en français. Bien que les mots « dot» et « trousseau » soient différents, on peut dire que le deuxième (le trousseau) entre tout simplement dans le premier (la dot), c'est-à-dire que le trousseau peut être une forme de dot. Or, ce trousseau, présenté comme modique dans les travaux sur l'histoire de la famille japonaise, a gagné en

3. BeilleVaire, 1986a, p. 300.

4. Ibid., p. 321.

5. Ibid.

6. MACÉ \& MACÉ, 2009 [2006], p. 263. 
importance avec le temps et il est encore réputé dans certaines régions pour l'effort financier qu'il représente lors du mariage des filles.

C'est le cas par exemple du département d'Aichi, produit de l'amalgame des anciennes provinces d'Owari, où se trouve la ville de Nagoya, et de Mikawa ${ }^{7}$, où l'on dit que ${ }^{8} \ll$ si tu as trois filles, le faîte du toit tombera » (musume sannin moteba, yanemune ochiru 娘三人持てば屋根棟落ちる). Dans ce département, les yomeiri dōgu servent d'ailleurs souvent d'illustration dans les manuels d'ethnologie tant ils sont célèbres. «Même de nos jours, la région allant du département de Toyama au département d'Aichi est connue pour le fait que l'on y apporte autant de yomeiri dōgu que possible », peut-on lire dans le chapitre consacré aux biens des femmes dans L'Ethnologie du point de vue des fermmes'.

Le but de cet article est de réévaluer l'importance de la dot dans les mariages au Japon en se concentrant sur cette pratique du $\mathrm{Xx}^{\mathrm{e}}$ siècle à aujourd'hui. La première partie montrera la complexité du sujet à travers le contenu du trousseau et la manière dont il a évolué, en prenant en compte les variables régionales, sociales et historiques. Elle s'appuiera sur deux mariages ayant eu lieu avant (dans les années 1930) et après la fin de la Seconde Guerre mondiale (fin des années 1960) dans la région de Nagoya. Dans une deuxième partie, nous analyserons la fonction de ces trousseaux en les comparant notamment aux pratiques qui se rencontraient en France dans les Pyrénées afin de montrer l'importance qu'il convient de leur accorder à l'époque contemporaine. Enfin, on montrera que la question de l'existence de la dot n'est pas nécessairement obsolète de nos jours et reste pertinente notamment à travers le financement des études.

Pour ce faire, on se fondera essentiellement sur la littérature folklorique locale ainsi que sur les résultats d'une enquête de terrain menée entre 2005 et 2008 pour la rédaction d'une thèse sur le sens du mariage dans la société japonaise actuelle. Cette enquête comprenait un peu plus de quatre-vingt études de cas qui ont été complétées par des entretiens supplémentaires impliquant une dizaine de

7. La rivière Sakai 境川 est considérée comme la ligne de démarcation entre les deux.

8. Propos recueillis par l'auteur de l'article que l'on retrouve dans les ethnographies du département d'Aichi de Hattori Makoto 服部誠. Hattori, 2001b, p. 208.

9. Kuraishi, 1999, p. 118. 


\section{CIPANGO \\ 300 Cahiers d'études japonaises $n^{\circ} 23$}

personnes réalisés en 2015 dans le but d'approfondir certains points de l'enquête initiale.

\section{Les trousseaux dans la région de Nagoya}

\section{L'bistoire d'I. T.}

I. et T. sont les initiales du nom et du prénom d'une interlocutrice née en 1943 qui s'est mariée en $1969^{10}$. Son histoire permettra au lecteur de se forger une image de ce que les trousseaux sont dans la région de Nagoya.

I. T. est l'avant dernière d'une fratrie de neuf enfants. Ses parents avaient une boutique de riz à Jimokuji 甚目寺 (commune située à l'ouest de Nagoya ayant fusionné avec celles de Miwa 美和 et de Shippō 七宝 pour former la ville d’Ama あま). Comme ses parents étaient très occupés par leur travail, elle fut chargée très jeune de s'occuper de la cuisine et c'est avec fierté qu'elle déclare pouvoir préparer de la soupe Tonjiru 豚汁 ${ }^{11}$ pour cent personnes.

Son époux, lui, habitait à Miwa où il était photographe. Leur mariage fut le résultat de l'intervention d'un entremetteur qui n'était pas un proche. Il fut l'œuvre d'un paysan qui ne manquait pas de montrer la photo de jeunes personnes à marier lors de ses déplacements :

Jadis, il y avait de telles personnes. Mon entremetteur était une personne qui montrait des photos dans divers endroits. Il n'avait pas de lien particulier avec moi. [...] C'était un paysan.

$$
\text { 昔、そういう人がいたわ。仲人さんはいろんなところ }
$$
で写真を持って歩いていた人でした。別に特別関係がな い人でした。(...) 農家でした。

10. Les personnes ayant contribué à l'enquête par leur témoignage seront désignées par leurs initiales afin de protéger leur anonymat.

11. Soupe à base de porc et de légumes mijotés avec du miso. 
Sur la liste (mokuroku 目録) de son trousseau, on peut lire qu'I. T. amena pour son mariage deux armoires (tansu 箪笥), une armoire pour les vêtements occidentaux ( $y \bar{o}$-dansu 洋箪笥), une commode à tiroirs pour le rangement (seiri dansu 整理箪笥), deux bahuts (nagamochi 長持ち), un porte kimono (ikō 衣 桁), une armoire pour mettre les ustensiles à thé ou la vaisselle (chadansu茶篂笥), une coiffeuse (kyōdai 鏡台), de l'électroménager dont notamment un ventilateur, une machine à coudre, un radiateur, une machine à laver et un aspirateur, ainsi qu'une planche pour la confection de vêtements (shitate-ita 仕立て板), une table basse (handai 飯台), un vélo (jitensha 自転車) et enfin un meuble à chaussures (getabako下駄箱). Le tout fut monté sur un camion décoré d'un tissu à larges raies verticales rouges et blanches et le chargement fut fixé grâce à d'imposantes bandes de tissus de la même couleur. L'ensemble de son trousseau put être installé sur un seul camion, mais le plus fastueux qu'il lui ait été donné de voir mobilisa sept véhicules. Normalement, ces camions n'ont pas le droit de faire marche arrière et on indemnise les automobilistes qui pourraient obstruer leur passage pour qu'ils les laissent passer.

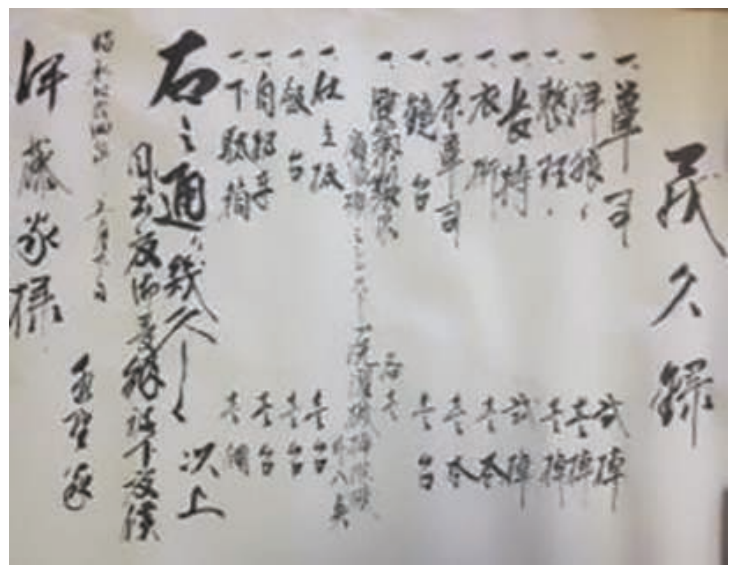

LISTE DES AFFAIRES LES PLUS IMPORTANTES APPORTÉES PAR I. T. 


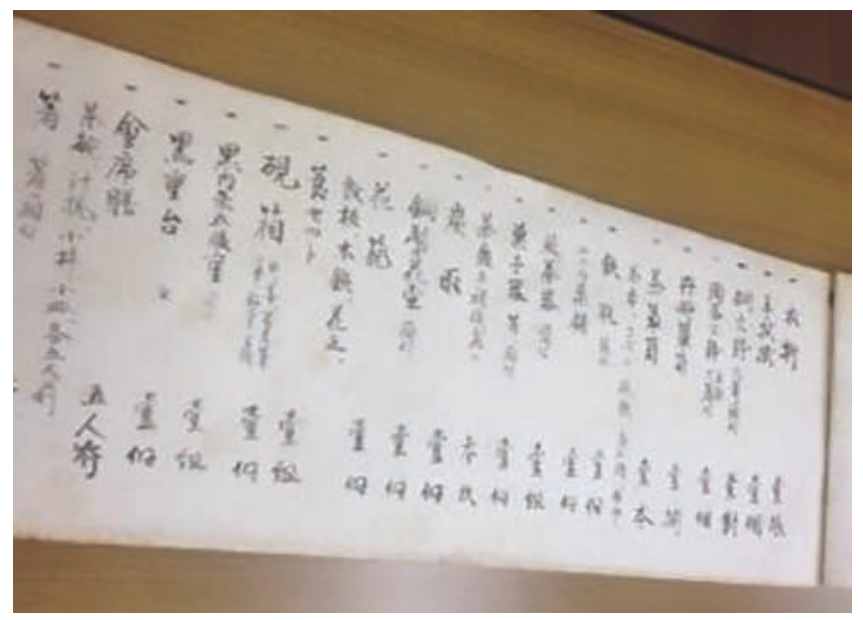

\section{PAGE UNE DE LA LISTE DÉTAILLÉE DES AFFAIRES DE SA BELLE-MÈRE.}

La liste présentée ci-dessus ne concerne que les éléments les plus importants du trousseau d'I. T. Il lui semble qu'il en existait une deuxième détaillant le contenu des différents meubles qu'elle apporta avec elle pour emménager chez son époux, mais on ne sait pas où le document se trouve actuellement. I. T. avait cependant en sa possession un document faisant état du menu détail du trousseau de sa belle-mère lors de son mariage en 1932 avec le père de son époux jadis directeur d'école, liste qu'elle avait confiée aux archives de Jimokuji. Sur les sept pages manuscrites qui la constituent, chaque type d'objet est minutieusement consigné : cent dix-huit entrées en tout.

On peut y apprendre que la mère de son époux apporta de très nombreux kimonos : trente-sept kimonos doublés (awase kimono 袷着物) dont trois au bas décoré marqués de blasons en haut (suso moyō montsuki 裾模様紋 付), deux kimonos habillés à motifs continus (bōmongi 訪問着, littéralement 《kimonos de visite »), trois kimonos en crêpe de qualité (omeshi 御召), ainsi que trente kimonos légers (bitoemono 単物), vingt-sept manteaux de kimono (haori 羽織), trois manteaux de kimono d'été (natsubaori 夏羽織), au moins vingt-et-une ceintures (obi 帯). Le souci de minutie va jusqu’à indiquer que le trousseau comprenait aussi vingt-trois hauts de sous-vêtements de kimono 
(hanjuban 半襦袢), vingt-sept bas de sous-vêtements de kimono (koshimaki 腰 巻), trente-neuf paires de chaussettes japonaises (tabi 足袋), vingt-sept tabliers (maekake 前掛), quinze essuie-mains (tenugui 手拭), vingt-huit articles de maquillage (keshōhin 化粧品), huit peignes en buis (tsuge kushi ツゲ櫛), vingt-deux ornements de coiffure (kami kazari 髪飾) ou encore deux savons (sekken 石鹸).

La belle-mère d'I. T. venait d'une famille de Nagoya qui s'occupait d'un bureau de poste (il s'agissait d'un commerce privé à l'époque). Le mariage s'était noué lorsque le père de son mari avait dû se rendre dans cette grande ville avant d'exercer à Miwa. Le détail du trousseau montre aussi qu'elle apporta un nombre de pièces de mobilier assez important : deux braseros d'intérieur (bibachi 火鉢), une bonbonnière (kashiki 菓子器), une corbeille à fleurs (hanakago 花籠), des boîtes de cinq étages pour servir les mets propres au Nouvel An (godanjū 五段 重), des plateaux sur lesquels les invités mangent leur repas (kaisekizen 会席膳), des paniers pour mettre les vêtements avant d'entrer dans le bain (midare kago ミ ダレ籠), etc. Cela s'explique par le fait que le couple s'installa dans une maison indépendante et non pas avec la famille du mari qui gérait une affaire de cactus. Enfin, on trouve dans la liste détaillée de ce trousseau divers accessoires de koto, si bien qu'il n'est pas insensé de supposer que le trousseau en comprenait un.

Cet exemple est bien documenté mais il ne s'agit cependant que d'un seul cas à un certain moment de l'histoire dans une localité et un milieu particuliers. Il est donc nécessaire de le mettre en perspective d'un point de vue régional, historique et social.

\section{Variable régionale}

Jimokuji et Miwa se trouvent juste à l'ouest de Nagoya dans la partie occidentale de l'ancienne province d'Owari. Il y avait cependant de multiples disparités à l'intérieur du département où se trouve cette agglomération. Cela est perceptible dans les travaux de Hattori Makoto 服部誠, qui a sillonné le département d'Aichi pour en recueillir les anciennes coutumes matrimoniales.

La narratrice I. T. mentionna, par exemple, que les personnes à l'origine de son mariage n'étaient pas des parents mais des agriculteurs qui montraient des photos et proposaient des partis. Les entremetteurs qui arrangent les mariages 


\section{CIPANGO}

304 Cahiers d'études japonaises $n^{\circ} 23$

sont normalement appelés nakōdo 仲人, c'est-à-dire la personne qui s'entremet, mais on parle plutôt d'ochünin dans le département d'Aichi, une lecture différente des idéogrammes utilisés pour écrire nakōdo auxquels un «o » de déférence a été ajouté.

Dans la partie ouest du département, il arrivait que ce rôle incombe à des parents, mais on avait aussi beaucoup recours à des « spécialistes » de la question qui aimaient s'occuper des autres, qui étaient amenés à sillonner la région pour leurs affaires, ou qui avaient beaucoup de relations. Ces entremetteurs recevaient normalement environ dix pour cent de l'argent des fiançailles que la famille du futur marié remettait à celle de la jeune fille dont elle demandait la main ${ }^{12}$. Cette somme était liée à celle dépensée pour la constitution du trousseau. En effet, l'argent des fiançailles n'avait pas vocation à être conservé par les parents de la jeune fille. La norme était qu'ils le redonnent à leur fille et qu'ils y ajoutent une contribution équivalente ${ }^{13}$.

On peut penser que les intermédiaires qui recevaient un pourcentage indexé sur l'argent des fiançailles aient eu intérêt à recommander aux familles de dépenser un peu plus que nécessaire pour que leur commission soit plus substantielle et les trousseaux s'en soient trouvés grossis ${ }^{14}$.

Il en allait autrement dans la partie est du département correspondant à l'ancienne province de Mikawa où les entremetteurs avaient une autre particularité : ils étaient doubles. Chaque famille en avait un pour le représenter alors que d'habitude les deux maisons partageaient le même. Les entremetteurs dans cette zone géographique étaient normalement recrutés dans la parenté. Dans le Nord du Mikawa montagneux, on demandait donc à une personne influente du village ou à une personne du réseau de maison-mère (bonke 本家)/maisonbranches (bunke 分家) auquel on appartenait de s'en occuper ${ }^{15}$. Dans le reste du Mikawa (en dehors de la péninsule d'Atsumi), on s'adressait à des parents proches

12. Hattori, 2001b, p. 213.

13. Ibid.

14. Ibid.

15. HATtORI, 2005 , p. 558. 
même s'ils n'habitaient pas dans la même commune : les liens de sang primaient sur la proximité géographique ${ }^{16}$.

Hattori évoque aussi le rôle du textile dans la constitution des trousseaux. La plaine fertile de l'Ouest de l'Owari, Okazaki ou encore Toyohashi bénéficiaient de ce type d'industrie légère. Cela dépendait sûrement des employeurs, mais les jeunes filles qui travaillaient dans des manufactures de textile pouvaient gagner plus d'argent que les jeunes femmes qui étaient domestiques. Une femme originaire de Bisai 尾西, née en 1915, donna les chiffres suivants à Hattori alors qu'elle expliquait pourquoi elle avait choisi de travailler dans une manufacture :

C'est parce que, dans le cas des manufactures de textile, on pouvait se faire environ 170 yens en six mois, alors que le salaire annuel d'une domestique était de l'ordre de 100 yens.

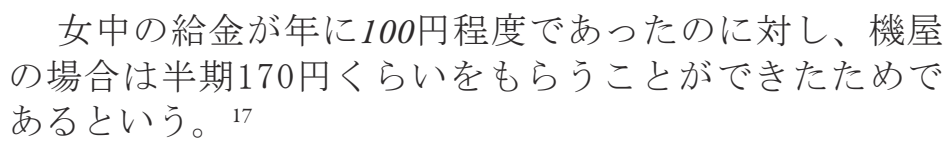

Les jeunes apprenties dans les manufactures de textiles bénéficiaient aussi d'un autre avantage non négligeable : elles avaient droit à des bonus. Il pouvait s'agir d'argent ou de coupons. Au bout d'un an, on leur donnait par exemple une commode, puis des futon, etc. Cela soulageait leurs parents de certaines dépenses et concourait à rendre les trousseaux particulièrement volumineux ${ }^{18}$.

Les travaux de Hattori ${ }^{19}$ révèlent par ailleurs que dans la partie est de l'Owari (propos recueillis dans la ville d'Owari Asahi 尾張旭), le trousseau des jeunes mariées issues d'une famille de paysans comportait une réserve de riz correspondant à la quantité nécessaire pour se nourrir pendant une année, période au bout de laquelle la jeune épouse était alors considérée comme un membre de la famille de

16. Ibid., p. 560.

17. Hattori, 2001 b, p. 217.

18. Ibid., p. 217-218.

19. Hattori, 2002, p. 132. 
son époux ${ }^{20}$. Signalons à ce propos qu'il y avait des endroits où le trousseau était différé à cause du type de mariage qui s'y pratiquait. C'est le cas par exemple à Shinojima 篠島, où on parle encore de mariage 《 par visites ( kayoi-kon カヨ 个婚). Dans ce type de mariage, la cérémonie de mariage n'est pas suivie par une résidence virilocale du couple. L'épouse retourne chez ses parents où son époux vient lui rendre visite et passer la nuit. Ce n'est que bien plus tard (généralement une à trois années) que l'épouse s'installe dans la maison de son mari ${ }^{21}$.

La lecture des travaux de Hattori donne à penser que la géographie (plaine ou montagne, terres fertiles ou pas), l'économie (présence ou absence d'une industrie légère) et l'organisation sociale et familiale qui en découle (entremetteurs venant de la parenté ou semi-spécialistes, agrégation directe ou différée de la future épouse) variaient d'un bout à l'autre du département. Tous ces éléments avaient un impact sur les trousseaux et peuvent expliquer que, par exemple, les jeunes filles de la partie ouest de l'Aichi où se trouve Jimokuji aient pu éventuellement bénéficier d'un trousseau plus important que dans le reste du département. Il n'y a cependant pas de raison de penser que la diversité régionale observable dans ce département ne se retrouve pas à l'échelle nationale. De plus, même dans la partie ouest du département, les trousseaux des jeunes filles n'ont pas toujours été aussi conséquents. Les variables historique et sociale rendent aussi l'appréciation de la dot complexe.

\section{Variables historiques et sociales}

Les témoignages recueillis dans l'ancienne commune de Fujioka 藤岡 (actuellement intégrée à Toyota) auprès des plus anciens ont révélé qu'il arrivait de leur temps qu'une jeune fille se rende chez son futur époux avec, en tout et pour tout, un simple baluchon. C'est ce que l'on appelait les « mariées au baluchon » (furoshiki-yome 風呂敷嫁). Elles étaient présentes dans tout le département.

20. Une pratique similaire est signalée après la guerre dans le Sud-Est du département où il arrivait aussi que l'on donne un peu de terre à la jeune mariée pour qu'elle l'exploite. Voir Hattori, 2003, p. 156.

21. Hattori, 1998, p. 130-131. 
Hattori se réfère d'ailleurs à des documents venant de la ville de Jimokuji où habite I. T. pour montrer le caractère relativement récent des trousseaux dans la région :

Jadis, dans les fermes ordinaires, les baluchons étaient nombreux. Une jeune bru venait sans qu'on le sache et le lendemain on appelait le voisinage pour [le rituel des] botamochi ${ }^{22}$. Les vrais mariages par prise de la bru, il n'y avait que dans les classes au-dessus des propriétaires terriens que l'on en faisait.

昔は、普通の農家では風吕敷包みが多く、知らぬ間 に嫁さんが来ているという有様で、翌日、牡丹餅（の儀 礼）で近所を招くくらいで、嫁入りらしいのは少なくと も地主以上であった ${ }^{23}$ 。

À Jimokuji, les trousseaux n'étaient pas fastueux avant le début de l'ère Taishô (1912-1926), commente Hattori. On lit aussi sous sa plume, dans La Nouvelle Rédaction de l'histoire de la ville de Nagoya (Shinshū Nagoyashi-shi 新修名古屋市 史), que c'est à partir du début de l'ère Shōwa (1926-1989) qu'il est généralement devenu rare de ne pas donner d'armoires aux jeunes filles au moment de leur mariage, même si cela représentait un effort financier important pour les parents ${ }^{24}$. Tout cela indique que le trousseau a une existence ancienne au Japon, mais qu'il a été limité aux classes sociales les plus élevées pendant un certain temps. Le fait que le trousseau ait longtemps été l'apanage de l'élite contribue sûrement à expliquer pourquoi la dot a tendance à être considérée comme insignifiante d'une manière générale.

La vulgarisation de la pratique du trousseau ne semble cependant pas s'être déroulée de la même façon en zone rurale et en zone urbaine. Hattori opère une distinction entre les deux car c'est en ville qu'il a observé les plus grands écarts de richesse entre les familles et donc une plus grande hétérogénéité dans la pratique du trousseau. Dans les campagnes, la norme était d'apporter une armoire et un

22. Mochi fait avec du riz gluant recouvert de pâte de haricots rouges.

23. HatTori, 2008, p. 555.

24. Hattori, 2001 a, p. 518. 


\section{CIPANGO}

308 Cahiers d'études japonaises n²3

bahut, les plus riches allant jusqu'à trois meubles ${ }^{25}$. Dans les annexes de l'ouvrage où figure l'essentiel des différents entretiens ayant servi de base à La Nouvelle Rédaction de l'histoire de la ville de Nagoya, on constate par contre des écarts plus impressionnants en ville. Une femme y expliquait que :

Mes parents n'ont apporté que des vêtements deux ou trois jours avant car je n'en avais pas beaucoup. Nous ne l'avons pas montré au voisinage non plus. Il n'y avait vraiment que les riches qui faisaient cela.

着るもののみであり、そんなになかったので二ー三日 前に親が持ってきた。エリカザリなどもしなかった。こ れはよほどの金持ちしかやらないものである26。

Quelques lignes plus loin, une autre femme issue d'une maison de commerçants livre en revanche un témoignage bien différent :

Le trousseau que la narratrice née en 1902 apporta lors de son mariage en 1921 comprenait treize $t s u r i^{27}$. Elle prépara entre autres une (ou des) armoire(s) de rangement entièrement laquée(s) de couleur marron et une (ou des) armoire(s) de salon en paulownia.

明治三五年生まれの話者が大正一○年に結婚した際の 嫁入りの荷物は十三釣りで、総塗り茶色の蔵入り箪笥、 桐の座敷箪笥などを用意した ${ }^{28}$ 。

Ces différents paramètres rendent l'étude du trousseau complexe car cette coutume n'a pas eu la même importance selon les milieux socio-économiques, même si elle s'est généralisée à partir de l'ère Taishō. On se souviendra par ailleurs

25. HATtORI, 2002, p. 132.

26. HATtoRi, 2009, p. 781.

27. [NDT] Unité pour compter les meubles les plus importants du trousseau tels que les armoires ou les bahuts.

28. Hattori, 2009, p. 781. 
que le contenu des trousseaux des deux générations de femmes de la même famille détaillés au début de cette partie a évolué.

Les trousseaux se sont tout d'abord enrichis d'appareils électroménagers à partir des années 1960 : aspirateurs, machines à laver, réfrigérateurs, fours, autocuiseurs, etc. La grand-mère d'une famille de trois générations (famille $\mathrm{O}$.) de Kamiyahagi 上矢作 (commune absorbée par la ville d'Ena 恵那 située dans le département voisin de Gifu) racontait l'admiration que suscita l'arrivée de ses affaires lorsqu'elle s'installa dans la maison de son mari. Le mariage avait eu lieu un $1^{\text {er }}$ février au début des années 1960 (1961 ou 1962) et la vieille dame se souvenait qu'il y avait beaucoup de neige ce jour-là. Comme ses parents tenaient un magasin d'électroménager, ils lui avaient donné des appareils encore rares dans le village de son époux : «Ce qui était exceptionnel, d'abord, c'était la machine à laver. Et puis, l'aspirateur aussi, c'était exceptionnel. » Cet aspirateur suscita d'ailleurs beaucoup de curiosité. Comme les gens du village n'avaient jamais vu d'aspirateur, tout le monde est venu le voir en disant « prête-le-moi s'il te plaît. » En plus de l'électroménager, d'autres types d'objet firent leur apparition parmi les affaires apportées par les mariées : les machines à coudre ou les vélos. Cette pratique est indiquée dans la Nouvelle Rédaction de l'histoire de la ville de Nagoya:

Après la guerre, il y a eu des gens qui apportaient une machine à coudre ou un vélo. Par ailleurs, souvent les armoires traditionnelles ont été remplacées par des armoires occidentales, les coffres sont devenus des commodes pour les futon, etc.

戦後では、ミシンや自転車を持ってゆく人もあり、ま た、篂笥が洋服ダンスになったり長持が縦長持 （布団篂 笥）になったりする ${ }^{29}$

Aujourd'hui, on parle plutôt d'automobile. Une femme (A. T., mariée en 1997) originaire de Nagoya, mais installée avec son mari à Miwa 美和 (commune situé à l'ouest de Nagoya), commentait les photos de son mariage ainsi :

29. HATTORI, 2001 a, p. 518. 


\section{CIPANGO \\ 310 Cahiers d'études japonaises $n^{\circ} 23$}

Il y avait aussi une voiture. Les gens qui ne conduisent pas n'en ont pas besoin mais, la voiture, si on veut se déplacer par soi-même... Pour aller chez ses parents, pour aller faire des courses...

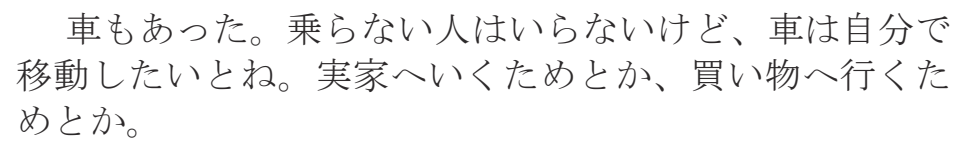

車もあった。乗らない人はいらないけど、車は自分で 移動したいとね。実家へいくためとか、買い物へ行くた めとか。

Tel fut aussi le cas de F. Y., née en 1975 et mariée en 2006. La mère de son époux habitait Owari Asahi 尾張旭, une ville de campagne située au nord-est de Nagoya. Elle pria sa bru d'acheter une voiture pour que la jeune femme puisse venir lui rendre visite et se déplacer dans les environs, car il était question que le couple s'installe chez elle ou fasse construire à côté ultérieurement.

L'évolution du contenu du trousseau contribue aussi à rendre son étude complexe. On retiendra que les vêtements et les armoires en constituaient l'essentiel, mais qu'ils ont suivi le développement économique du pays. Dans la partie suivante, on se demandera quelles étaient les fonctions des trousseaux composés d'armoires et de kimonos, lorsqu'il est devenu normal d'en fournir un aux filles à l'occasion de leur mariage.

\section{Une fortune en étoffe}

Il convient de se rappeler que les étoffes avaient jadis une grande valeur. Elles ont été un moyen d'échange privilégié dans certaines cultures, une sorte de monnaie. Notons à ce sujet qu'au Japon aussi le tissu fut autrefois un moyen privilégié d'effectuer des transactions d'ordre financier. Cela se constate de manière évidente dans l'Antiquité. Le Japon commence à se doter vers le viI ${ }^{\mathrm{e}}$ siècle de codes administratif (ritsu 律) et pénal (ryō 令) sur le modèle chinois. Ceux-ci fixent trois sortes d'impôts. Tout d'abord un impôt en riz ( $s o$ 租). Ensuite, les corvées ( $y \bar{o}$ 庸) qui consistaient à travailler 10 jours ou à s'acquitter de cette charge en sel, en riz, en tissu ou en coton. Enfin, le tribut ( $c h \bar{o}$ 調) qui était essentiellement en pièces de tissu, mais qui pouvait aussi être réglé sous la forme de produits régionaux. On tenta à plusieurs reprises de mettre aussi en circulation de la monnaie, mais 
cette unité de compte ne parvint pas à remplacer celles du riz ou du tissu plus couramment utilisées :

La première émission (de la monnaie) eut lieu en 708 et d'autres ont suivi jusqu'au milieu du $\mathrm{X}^{\mathrm{e}}$. Mais, malgré les incitations officielles qui allèrent jusqu'à vendre des rangs à ceux qui accumulaient la monnaie, elle a peu circulé, s'est rapidement dévaluée et n'a pas remplacé, tant s'en faut, le système du troc. Boisseaux de riz ou pièces de tissu sont restés des unités de compte plus utilisées que la monnaie. Il n'existait en effet qu'un mince courant d'échanges, nécessaire car les fonctionnaires payés en riz, tissu ou houes devaient bien les troquer contre d'autres produits ${ }^{30}$.

Chacun de ces différents moyens d'échange présentait des avantages et des inconvénients différents. En ce qui concerne la monnaie de tissu ${ }^{31}$, considérons tout d'abord qu'elle pouvait être utilisée pour remplir un besoin fondamental, celui de protéger le corps. Ensuite, elle était assez facilement transportable, ce qui n'était pas négligeable lorsque l'on souhaitait procéder à des échanges. Elle était aussi ajustable puisqu'il est possible de couper le tissu. De plus, il était facile de l'accumuler et de la conserver car les étoffes durent longtemps. Enfin, dans le cas de tissus teints ou décorés, on peut dire que chaque unité de compte était identifiable car elle se distinguait des autres, contrairement aux pièces qui ont toutes la même forme ou aux grains de riz tous semblables. Les kimonos du trousseau de la mariée faits de tissu présentent les mêmes avantages. Il semblerait donc justifié de les considérer comme des unités de compte représentant une petite fortune personnalisée contenue dans les coffres forts que sont les armoires.

La valeur de ces armoires peut par ailleurs notoirement varier selon le bois utilisé. Dans la région de Nagoya, le paulownia est symbole de qualité, car ce bois est réputé en tant que moyen de protéger naturellement les kimonos de l'humidité. Nagoya est d'ailleurs un centre de production de ce type d'armoires. D'après

\section{Hérail, 1990, p. 75.}

31. Voir le travail de Shimada, 2003, p. 98. Dans cet ouvrage, l'auteur disserte entre autres sur les avantages des monnaies de tissu. 
312 Cahiers d'études japonaises $n^{\circ} 23$

l'ouvrage Traditions du département d'Aichi pays natal (Aichiken furusato no dentō 愛知県ふるさとの伝統), l'histoire de cette industrie locale remonterait à la construction du château de Nagoya et à l'afflux d'artisans charpentiers que les travaux entrainèrent ${ }^{32}$. Toutes les armoires de ce type ne se valent cependant pas. On trouve, dans les documents de la Nouvelle Rédaction de l'histoire de la ville de Nagoya, que l'on établissait une différence entre les armoires dont seuls la façade et les côtés étaient en paulownia et celles entièrement faites en cette noble matière ${ }^{33}$. Le bois utilisé ou encore la finition (on nous parla lors d'une rencontre visant à recueillir différents entretiens de l'utilisation de clous en bois ou ordinaires) avaient leur importance dans l'appréciation de la valeur du trousseau.

Il a été souligné que les kimonos et les armoires étaient une forme de fortune. Notons aussi que certains kimonos étaient frappés d'un blason. Il s'agissait alors de celui de la famille natale de la jeune épouse. Pour Hattori Makoto, le but était de rendre clair aux yeux de tous que c'est la maison natale de la femme qui les avaient préparés ${ }^{34}$. D'autres chercheurs vont plus loin. On peut aussi considérer qu'il s'agissait, en effet, d'un moyen de montrer que ces kimonos appartenaient à la famille de la bru et non pas à celle de l'époux. Les affaires de la mariée étaient d'ailleurs normalement restituées dans le cas où le lien marital était rompu. C'est sûrement pour cette raison qu'elles étaient consignées avec autant de minutie. On retrouve cette explication dans l'entrée rédigée par Nakagomi Mutsuko 中込 睦子 sur les biens dotaux (jisan zaisan 持参財産) du Dictionnaire de la famille (Kazoku-jiten 家族一事典) :

En principe, les biens dotaux appartiennent à la bru et ne rentrent donc pas dans le patrimoine de la maison de son époux. C'est pour cela que l'on trouve les blasons de la famille de la maison natale ou le blason de la femme sur les kimonos pour les grandes

32. Fūdosha, 1987, p. 219.

33. HATTORI, 2009, p. 780.

34. « Pour ce qui est du blason, on mettait celui de la maison natale; on montrait aux yeux de tous que [ces kimonos] avaient été mis à disposition par la maison natale [de la jeune épouse] 紋付には在所の家紋を入れ、在所で用意したものであることを 明らかにした。»(HATTORI, 2001a, p. 518). 
occasions ou sur les meubles. En cas de divorce, toutes les affaires de la mariée seront retournées à sa maison natale ${ }^{35}$.

持参財は原則として嫁個人に帰属するものであり、婚 家の財産に組み入れられるわけではない。晴れ着や調度 品に実家の家紋や女紋をつけるのはこのためであり、離 婚に際しては嫁入り道具はすべて実家に返される。

Non seulement ces biens restaient sous le contrôle de la famille de l'épouse, mais cette dernière pouvait en faire l'usage qu'elle souhaitait. Elle pouvait les vendre si bon lui semblait. C'est en effet ce que fit H. T. (octogénaire en 2008) juste après la fin de la Seconde Guerre mondiale, quand le pays manquait de tout pour acheter de la nourriture, ce qui provoqua bien du dépit à sa mère : «j'ai vendu les kimonos que ma mère s'était donné tant de mal à me procurer et j'ai acheté du riz avec cet argent. » Les kimonos avaient plus de valeur que du numéraire en ce temps-là ${ }^{36}$.

Les femmes pouvaient aussi décider de les thésauriser. Certes, les vêtements pour la vie quotidienne se déchirent à cause de l'usure. Les pièces d'apparat, par contre, ne sont que rarement sorties des tiroirs. Il est donc possible de les transmettre à la génération suivante. Cela est particulièrement facile à faire dans le cadre du Japon car, contrairement aux robes occidentales, les vêtements japonais ne sont pas faits sur mesure. De ce fait, une mère peut donner ses kimonos à ses filles sans problème, pour peu qu'elles aient à peu près la même taille. Une femme que l'on appellera K. K. (née en 1939) nous expliqua qu'elle a porté le kimono de mariage de sa mère lors de ses propres noces dans les années 1960. Il s'agissait d'un kimono noir avec de grands motifs dans le bas. La mère de K. K. le lui donna car les noces de K. K eurent lieu à Paris et que sa mère ne pouvait pas faire le voyage. Cinq ans avant sa mort, la mère de K. K. entreprit de faire restaurer les meubles de son trousseau, ce qui lui revint très cher. Elle inscrivit ensuite sur son testament qu'elle désirait que ses deux armoires et sa coiffeuse reviennent à chacune de ses

35. Hikaku KazokU-Shi gakKai, 1996, p. 392.

36. Kuraishi, 1999, p. 129. 


\section{CIPANGO \\ 314 Cahiers d'études japonaises $n^{\circ} 23$}

trois filles. Enfin, ajoutons que K. K. donna à son tour quelques kimonos à ses propres descendantes. Comme toutes les fortunes, celle des femmes pouvait être transmise à la génération suivante.

Toutes ces caractéristiques liées à la gestion du trousseau montrent que le destinataire de ce type de fortune féminine était au premier chef la femme mariée elle-même et éventuellement ses filles s'il restait encore quelques belles pièces. Alors que le Code civil de Meiji promulgué en 1898 établissait que le chef de famille devait être l'aîné, que le mariage signifiait pour la jeune fille d'entrer dans la maison de son époux, que l'épouse était incapable juridiquement, que cette incapacité « s'étendait également aux biens propres de l'épouse qui, par le mariage, passaient sous la gestion de son mari ${ }^{37} \gg$ au nom du devoir d'obéissance qu'elle lui devait et de la pérennité de la maison, on peut supposer que les jeunes épouses gardaient cependant dans la pratique le contrôle de leur fortune personnelle qu'était le trousseau.

\section{Une avance sur l'héritage}

Selon Goody, la fonction essentielle de la dot était d'assurer une certaine dévolution intergénérationnelle, c'est-à-dire de ne pas exclure totalement les femmes de l'héritage ${ }^{38}$. Pour lui, dot et héritage doivent être placés sur le même plan, la seule différence entre les deux étant que le premier type de dévolution a lieu au mariage alors que le deuxième prend place à la mort des parents.

Il a été indiqué qu'au Japon, c'est la maison natale de la future épouse qui préparait le trousseau, et on peut aussi effectivement parler d'une sorte d'avance sur héritage. I. T. dont il était question en début de première partie indique clairement que, dans son cas, le trousseau avait eu une telle fonction :

C'est mon héritage. C'est quelque chose comme cela. [...] Maintenant, avec le droit, on ne peut pas dire qu'il n'y ait que cela. Cela dépend des maisons, je pense, mais, avant, si une fille recevait

37. Konuma, 2011, p. 404.

38. Goody, 2001, p. 128. 
un trousseau au moment de partir de la maison, après elle ne disait plus rien. C'est pour cela qu'on m'a prise en photo avec mes affaires!

相続ですね。そういう感じです。 りまして、そういうことばかりと言えませんね。家によ って違うと思いますけど、昔、女がこれをもらって家を 出ていったら、後は何も言わないという感じですね。だ から私と荷物が写っているでしょう。

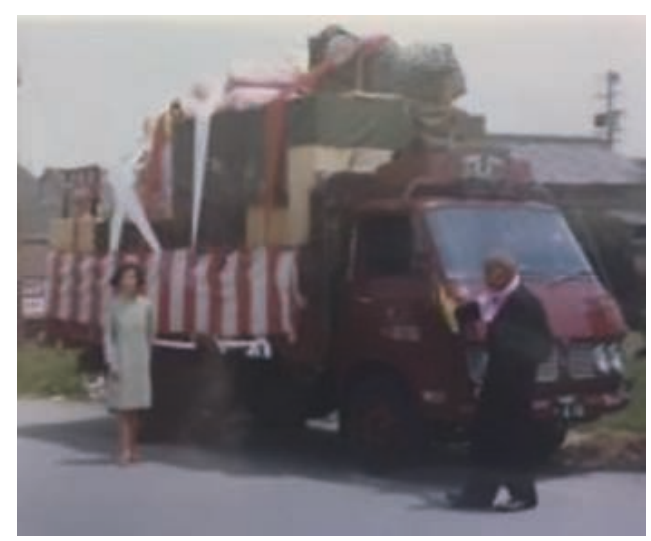

TROUSSEAU D’ I. T., JIMOKUJI, 1969.

Rappelons que la règle de la primogéniture mâle était préconisée dans le Code civil de 1898 qui allait s'appliquer à toutes les classes sociales et à toutes les régions. Cet héritage inégalitaire qui favorisait l'aîné des garçons étaient déjà pratiqué antérieurement mais pas avec la même intensité selon les classes sociales et les régions. C'est ce que Patrick Beillevaire explique dans son histoire de la famille japonaise :

[...] Cette législation restait fidèle, sur bien des aspects essentiels, aux principes qui avaient gouverné l'organisation domestiques traditionnelle, et plus particulièrement celle de l'ancienne classe militaire (l'influence samourai fut encore plus nette après la révision 


\section{CIPANGO}

316 Cahiers d'études japonaises n²3

du code en 1912). [...] Jusque-là, en effet, les mœurs paysannes avaient reposé sur des règles très variées et généralement moins astreignantes, aussi bien en ce qui concerne l'autorité paternelle que le statut de l'épouse ou les pratiques successorales ${ }^{39}$.

Dans cette organisation familiale qui avantageait l'aîné des garçons, les cadets avaient plusieurs possibilités. Ils pouvaient soit rester célibataires dans la maison des aïeux pour travailler sous les ordres du maître de maison, soit recevoir des terres de la part de leur famille pour fonder leur propre maison (une maison-branche, bunke 分家), soit devenir apprentis ou se placer chez d'autres agriculteurs ou encore essayer de trouver un emploi en ville ${ }^{40}$. Les filles, elles, se mariaient dans une autre maison.

Il pouvait arriver qu'une famille n'ait pas de descendant masculin. On mariait alors une des filles et on adoptait le gendre. Dans le Code de Meiji, le gendre adopté bénéficiait des mêmes droits qu'un enfant biologique. Il devenait donc légalement l'héritier de la maison de son épouse à la mort de son beau-père. Les brus, quant à elles, ne pouvaient prétendre à la succession de la maison de leur époux que si ce dernier mourait et n'avait ni frère ni soeur ${ }^{41}$. On peut donc dire que les filles étaient davantage exclues de l'héritage que leurs frères et on comprend que leur dot ait été, dans leur cas, une façon de les indemniser.

On s'étonnera cependant de la persistance de cette coutume après la fin de la Seconde Guerre mondiale. En effet, les changements apportés par la nouvelle Constitution entrée en vigueur en 1947 ainsi que par le Code civil modifié en 1948 sapèrent les fondements de l'ie 家, mot dont le contenu est proche de celui de « maison ». Ce terme ne doit pas être entendu ici comme une simple habitation : il renvoyait aussi à un patrimoine et à une organisation familiale ${ }^{42}$. Beillevaire indique que la définition de la «maison » de Lévi-Strauss vaut aussi pour l'ie : « personne détentrice d'un ensemble de biens à la fois matériels et immatériels qui

39. Beillevaire, 1986b, p. 321.

40. HiKAKU KAZOKU-SHI GAKKAI, 1996, p. 394.

41. Beillevaire, 1986b, p. 320.

42. Beillevaire, 1986a, p. 309. 
se perpétue par la transmission de son nom, de sa fortune et de ses titres, en ligne réelle ou fictive ${ }^{43}$. $\gg$ C'est pour mieux la transmettre que l'on évitait d'ailleurs de disperser les terres et que l'on avait recours à la primogéniture mâle. L'article 24 de la nouvelle Constitution qui prévoit une complète égalité entre les hommes et les femmes ${ }^{44}$ ainsi que les nouvelles dispositions du Code civil garantissant à tous les descendants une part égale d'héritage quel que soit leur sexe ou leur rang de naissance ${ }^{45}$ devaient alors vider l'ie de son essence.

Tout cela ne vint pourtant pas à bout de la coutume des trousseaux. L'histoire d'I. T. montre qu'ils étaient encore présents à l'aube des années 1970 et qu'ils étaient toujours considérés comme un héritage anticipé par une partie de la population. Même si la loi a été profondément remaniée après la Seconde Guerre mondiale, les anciennes façons de penser l'héritage ne semblent pas avoir disparu en pratique et la nouvelle règle de la dévolution égalitaire a pu être contournée par le biais d'arrangements intra-familiaux dont le trousseau a continué à faire partie.

\section{Les autres fonctions du trousseau}

Goody attribuait aussi une autre fonction à la dot : celle de maintenir le statut social des filles et de leur garantir un niveau de vie identique à celui de leur maison natale ${ }^{46}$. Concrètement, il s'agissait de faire un mariage dans un milieu social équivalent ou supérieur au sien et il ne semble pas que le Japon fasse figure d'exception à ce sujet.

Les mariages arrangés y ont été majoritaires jusqu'à la fin des années $1960^{47}$. Il est évident que les intermédiaires ne proposaient que des unions intéressantes pour les deux familles, sans quoi leurs services n'auraient eu aucune utilité. Hattori Makoto rappelle qu'on disait : tsuriawanai no wa fuen no moto 釣り

43. Ibid., p. 310.

44. Beillevaire, 1986b, p. 331.

45. Ibid., p. 332.

46. Ibid., p. 130.

47. Voir la troisième partie pour plus de détails. 
合わないのは不縁のもと ${ }^{48}$. Normalement, le verbe tsuriawanai indique le fait de ne pas s'équilibrer ou de ne pas être assorti. L'expression signifie d'une manière générale que «le déséquilibre est cause de rupture du mariage ». On se souviendra cependant qu'en ce qui concerne la région de Nagoya, le mot tsuri servait à désigner les meubles les plus importants du trousseau comme les armoires ou les coffres. On peut donc aussi comprendre tsuriawanai comme un déséquilibre portant sur les meubles du trousseau. Hattori explicite d'ailleurs que le nombre d'armoires apportées par la mariée était un symbole du rang social des maisons qui s'alliaient, et qu'il était important d'arriver à un accord à ce sujet.

C'était une manière pour les parents de gâter leur fille et ils avaient tendance à penser que cette dernière serait d'autant plus heureuse chez son époux que son trousseau était important ${ }^{49}$. D'un point de vue pragmatique, on peut imaginer que cela pouvait adoucir la vie de la bru dans la maison de son époux où elle devait obéir à ses beaux-parents et où elle avait peu de droits au début ${ }^{50}$. L'idée était par ailleurs que le trousseau posait socialement la jeune fille dans son nouvel environnement ${ }^{51}$. On se souviendra à ce titre de l'enthousiasme qu'avait provoqué la présence d'un aspirateur dans un trousseau alors que ce bien d'électroménager était encore rare. Un trousseau bien fourni pouvait probablement permettre à la bru de s'attirer les bons égards de son nouvel entourage.

Cela peut par ailleurs expliquer la surenchère à laquelle a pu mener la coutume erikazari エリカザリ 52 qui consistait à montrer le trousseau au voisinage. Il s'agissait d'une affaire sérieuse et Hattori Makoto conte une histoire amusante montrant l'importance de gonfler les trousseaux. En effet, une personne née à Ichinomiya 一宮 (nord-ouest de Nagoya) en 1911 lui raconta que :

48. Hattori, 2001 a, p. 518.

49. HATtoRi, 2001b, p. 226-227.

50. TADENuma, 1999, p. 48-49.

51. Hattori, 2001b, p. 227.

52. Le travail de Hattori ne mentionne pas les caractères utilisés pour écrire le nom de cette coutume. On peut cependant supposer que cela s'écrit 襟飾り, littéralement « la décoration du col » qui désigne un collier ou une broche que l'on met sur le col d'un vêtement occidental. 
Là-bas, le nombre de kimonos apportés faisait vite le tour des maisons, donc on se saignait autrefois aux quatre veines. C'était comme une sorte de compétition. Dans le cas où la fille aînée et sa cadette se mariaient en même temps, il y en a qui mettaient aussi la part de la cadette dans le trousseau que la fille aînée prenait pour la cérémonie de mariage afin de pouvoir se vanter d'avoir apporté beaucoup de choses. Le lendemain du mariage, les affaires étaient disposées, on appelait les voisines, puis quand la noce était finie, la cadette retirait sa part ${ }^{53}$.

あそこは何枚持ってきたといって噂になるので、昔は 無理をしてでかしたものであった。競争のようにしてい た。たくさん持ってきたことを自慢したいので、姉と妹 が一緒に話が決まったような場合、一緒に荷物をでかし て妹の分も姉の結婚式の時に持って行き、婚礼翌日に積 んでトナリを呼んで見てもらい、嫁入り過ぎると妹の分 を引き上げるような人もあった。

Enfin, Goody évoque une autre fonction de la dot, après celles de compensation et d'obstacle à une mésalliance : elle pouvait aussi servir à protéger la jeune épouse en cas de problème ${ }^{54}$. Il a été mentionné plus haut que la famille de l'époux se devait de restituer le trousseau en cas de divorce. On peut penser qu'au Japon aussi, la perspective de récupérer des biens sortis du patrimoine de la maison pouvait inciter les parents de l'épouse à la récupérer.

Dans le Japon du $\mathrm{Xx}^{\mathrm{e}}$ siècle, les biens donnés au moment du mariage n'étaient probablement pas que symboliques; ils avaient une utilité réelle qui concorde jusqu'ici avec les fonctions généralement attribuées à la dot. On se demandera cependant ce qu'il en est des terres ou des espèces.

53. HatToRi, 2001b, p. 227.

54. Goody, 2001, p. 143. 


\section{CIPANGO \\ 320 Cahiers d'études japonaises $n^{\circ} 23$}

\section{Propriétés terriennes et argent}

De la période des guerres intestines ${ }^{55}$ à l'époque moderne, il existait ce que l'on appelait les « frais de maquillage » (keshōryō 化粧料). On en trouve trace dans le Recueil des coutumes civiles du pays entier (Zenkoku minji kanrei ruishü 全国民事 慣例類集), compilation des différentes coutumes locales entreprise pour munir le Japon d'une constitution et d'un code civil au début de l'ère Meiji. Le recueil connut deux versions : une première en 1877 et une seconde en 1880.

S'agissant des « frais de maquillage », le recueil nous laisse des informations intéressantes. Par exemple, dans le district d'Atsumi 渥美郡 situé dans l'ancien pays de Mikawa, les biens des jeunes mariées étaient considérés de la façon suivante :

Des biens mobiliers et immobiliers appelés « frais de maquillage » constituent la dot. L'argent est enregistré sur la liste du trousseau et, en ce qui concerne les terres, on change le nom sur les registres chez le chef du village. Lors d'un divorce, le tout est en général restitué sauf en cas d'adultère de la femme. En dehors de cela, les droits et les obligations ne font l'objet d'aucune réglementation.

化粧料卜號シ動産不動産习嫁資トスル事アリ。金圓八 嫁具目録二記列シ田畑八庄屋二於イテ名寄帳ヨ書改ムル 事ナリ。若シ離縁ノトキ婦姦罪等ノ事アルヨ除クノ外ハ 皆差戻ス例ナリ。別二權義の定ナシ ${ }^{56}$ 。

Le recueil ne permet pas de savoir ce qu'il en était dans l'ancienne province d'Owari car les façons de traiter les biens apportés par les femmes pouvaient varier d'une région à l'autre. On retiendra toutefois de ce corpus que les terres et l'argent pouvaient connaître des traitements différents, qu'ils passaient parfois sous le contrôle de la famille de l'époux mais pas toujours, et qu'ils pouvaient aussi être attribués pour une seule génération, c'est-à-dire qu'ils retournaient dans le giron

55. 戦国時代 (fin $\mathrm{XV}^{\mathrm{e}}$ siècle - fin $\mathrm{XVI}^{\mathrm{e}}$ siècle).

56. Sнiнōshō, 1976 [1880], p. 53. 
de la maison de l'épouse lorsque le mariage prenait fin. Dans le cas où le droit de propriété n'était pas donné à l'époux, ces biens pouvaient être mis au nom de la jeune épouse mais, en général, la maison natale se réservait le droit de propriété ${ }^{57}$.

On ne peut pas conclure que les propriétés foncières et l'argent n'aient jamais fait part des biens donnés aux filles qui se mariaient. Tout comme pour le trousseau, il semble qu'un ensemble de précautions aient pu être prises pour que ce type de biens aussi serve à la bru elle-même et non à la famille de son époux.

On remarquera cependant qu'il n'a pas été question de propriétés terriennes ou d'argent dans les documents fournis par I. T. Le fait est que les femmes ayant contribué à l'enquête n'ont jamais mentionné de propriétés terriennes. Peut-être ont-elles cessé d'être économiquement intéressantes. En ce qui concerne l'argent, c'est une question assez délicate à cause notamment de ce que l'on appelle les hesokurikin 臍繰金 dont les caractères signifient littéralement « l'argent enroulé du nombril ». Ce terme désigne aujourd'hui des économies privées dont la nature secrète rend difficile l'identification de leur étendue, leur provenance ou encore leur utilisation.

Il est par ailleurs intéressant d'apprécier l'importance de ces biens en comparant le Japon à d'autres sociétés « à maisons » ayant pratiqué un héritage inégalitaire en faveur de l'aîné des garçons. C'est le cas en France, dans les Pyrénées par exemple, où se rencontrait la coutume de la dot. Les travaux de Frédéric Le Play au $\mathrm{XIX}^{\mathrm{e}}$ siècle sur l'organisation familiale de cette région dont il déplore la disparition progressive ont ouvert la voie à de nombreuses recherches ultérieures. La maison pyrénéenne est donc bien documentée et l'on sait que les coutumes pouvaient sensiblement varier d'un bout à l'autre de la chaîne des Pyrénées.

Agnès Fine, qui a travaillé sur la dot dans le Pays-de-Sault (Pyrénées audoises) où s'est pratiqué un droit dotal jusque dans les années 1940, souligne en tout cas la même volonté des parents de ne pas diviser le patrimoine de la maison. Elle indique par ailleurs que le don d'une dot entraînait un renoncement à la succession de la part de la jeune fille qui la recevait, car cette dot était là aussi considérée comme une sorte d'avance sur l'héritage. Il en résulte que la dot était souvent composée de biens meubles (argent, bétail, trousseau). Elle consistait parfois en biens fonciers,

57. Kondō, 1991, p. 66. 


\section{CIPANGO}

322 Cahiers d'études japonaises $n^{\circ} 23$

mais ces derniers n'étaient normalement que prêtés par la maison natale afin que la jeune épouse puisse les cultiver et disposer de leur récolte ${ }^{58}$. Enfin, si la femme était propriétaire de sa dot, c'est son époux qui en avait l'usufruit. Jusqu'ici, ces différentes caractéristiques de la dot dans les Pyrénées audoises se retrouvent aussi au Japon.

Agnès Fine indique cependant que la somme d'argent reçue ou promise à l'occasion de l'entrée d'une bru dans une maison pouvait être utilisée pour financer celle des frères et des sœurs de l'époux ${ }^{59}$. Pierre Bourdieu donnait un exemple concret de cette interdépendance des mariages dans Le Bal des célibataires, ouvrage dans lequel il revient sur les stratégies matrimoniales dans une autre région des Pyrénées, celle du Béarn ${ }^{60}$ :

Chez Tr., il y avait cinq cadettes. [...] Quand vint le moment de marier l'aîné, trois cadettes étaient déjà mariées. Le garçon aimait une fille de La. qui n'avait pas un sou. Le père lui dit : « tu veux te marier ? J'ai payé (pour) les cadettes, il faut que tu ramènes des sous pour payer (pour) les autres [...] $\gg^{61}$.

Ce dernier point montre que le numéraire pouvait être un élément décisif dans la conclusion d'un mariage, car il n'engageait pas seulement le destin d'un membre de la famille mais aussi celui de la fratrie. À l'inverse, une dot trop importante pouvait mettre en danger l'ensemble de la famille si cette dernière était amenée à devoir la restituer.

Derrière un même mot peuvent se cacher des réalités différentes. Ce genre de situation ne semble pas avoir été courant au Japon, où les biens donnés à l'occasion du mariage servaient surtout au bien-être de la bru. Il en allait de même pour l'argent que l'on gardait secret afin qu'il échappe au contrôle du chef de la maison de l'époux dans le cas où il régissait les finances de la maison. Le but

58. Fine \& LeduC, 1998, p. 33.

59. Ibid., p. 36.

60. Agnès Fine indique que l'analyse de Bourdieu vaut aussi pour le Pays-de-Sault.

61. Bourdieu, 2002, p. 188. Le mariage de l'aîné avait eu lieu en 1910. 
était bien entendu que la bru puisse l'utiliser plus librement ${ }^{62}$. Les biens dotaux qui restaient sous le contrôle de la jeune épouse et de sa maison natale n'avaient pas nécessairement vocation à être transmis à la descendance ou à jouer un rôle dans les stratégies matrimoniales futures. On ne peut pas dire que la dot était inconnue ou uniquement symbolique dans le Japon contemporain, mais elle n'y était pas déterminante. « D'une manière générale, les biens offerts à l'occasion d'un mariage n'étaient pas en eux-mêmes un prérequis à l'établissement d'un mariage »(一般にいえば、持参財そのものが婚姻成立の要件となるわ けではない), peut-on lire dans le Grand dictionnaire de la famille ${ }^{63}$.

De nos jours, les trousseaux n'ont cependant plus la même image. Qu'en est-il de la dot à l'heure actuelle?

\section{Nouvelles formes de dot}

\section{Disparition du trousseau?}

Lorsque la règle de l'héritage en faveur de l'aîné des garçons s'est imposée au Japon, on comprend que des systèmes de compensation aient pu se développer afin d'indemniser les enfants exclus. En ce qui concerne les filles, elles étaient normalement destinées à partir comme épouse (嫁に行く). Cela impliquait concrètement qu'elles étaient appelées à ne plus faire partie de leur maison natale après leur mariage et à ne plus avoir de droits en son sein. On a montré que le trousseau qu'elles recevaient était une forme d'indemnisation. La famille japonaise allait cependant connaître d'importantes transformations aux lendemains de la Seconde Guerre mondiale.

D'un point de vue juridique, les changements imposés au droit japonais devaient mettre fin à la notion de maison. On a vu précédemment que des arrangements ont sûrement permis de contourner les nouvelles lois, notamment celles relatives à l'héritage. Les changements juridiques ne sont cependant pas les seuls à avoir eu une influence sur l'organisation familiale du Japon.

62. Hikaku KazOKUSHI GAKKaI, 1996, p. 391.

63. Ibid., p. 393. 


\section{CIPANGO \\ 324 Cahiers d'études japonaises n²3}

Au niveau économique, l'entrée du pays dans ce que l'on appelle la « haute croissance économique » à partir du milieu des années 1950 eut aussi une incidence sur la famille. Cette nouvelle prospérité devait en effet marcher de pair avec un exode rural entraînant un éparpillement des familles et une augmentation du nombre de personnes tirant leurs revenus d'un travail salarié (60\% en 1965 contre $49 \%$ en $1955^{64}$ ) au détriment du secteur agricole. Le boom économique allait concrètement permettre aux cadets de se faire une place bien plus facilement et, paradoxalement, ce sont les héritiers de propriétés agricoles qui ont commencé à connaître des difficultés ${ }^{65}$. La taille moyenne des foyers allait par ailleurs se réduire, passant de 4,95 personnes pendant la décennie qui a suivi la guerre à 3,69 en 1970, à 3,33 en 1980, puis à 3 en $1990^{66}$.

Par ailleurs, la famille conjugale allait être érigée en modèle, notamment par les médias. C'est donc la relation de couple qui prit le pas sur les liens parents-enfants et les intérêts de la «maison ». Alors que les mariages dits «sur rencontres » (omiai kekkon お見合い結婚) sont restés majoritaires après la Seconde Guerre mondiale, ils devinrent ex aequo avec les mariages dits d'amour (ren.ai kekkon 恋 愛結婚) à la fin des années 1960. Ces derniers ne firent qu'augmenter par la suite si bien que l'on peut dire que l'on se marie essentiellement par inclination dans la société japonaise contemporaine ${ }^{67}$. Les sentiments étant par définition gratuits, il est logique que leur prédominance dans la conclusion des mariages ait éclipsé les considérations économiques dont la dot était une des composantes.

En ce qui concerne les modes de vie, les jeunes Japonaises d'aujourd'hui ont tendance à vouloir un trousseau de plus en plus réduit quand elles se marient. Cela est vrai à Nagoya comme sur l'ensemble du territoire. Les objets traditionnellement apportés par la mariée sont souvent perçus comme encombrants, car la taille et l'agencement des logements ont considérablement évolué :

\footnotetext{
64. Ibid., p. 338.

65. Ibid., p. 394.

66. Ibid., p. 334.

67. TaChibanaki, 2008, p. 134.
} 
[...] On peut constater une certaine tendance à ne plus accorder d'importance à ce que l'on appelle les affaires de la mariée. Bien que l'on dépense une somme importante pour la bague de fiançailles ou la bague de mariage, les meubles tels que les commodes qui constituaient les affaires de la mariée jadis ou les kimonos qu'elles contiennent, en arrivent même à être plutôt considérés comme étant encombrants en ville.
[...] 嫁入り道具といったものはほとんど重視されなく なる傾向が見られる。婚約指輪結婚指輪にはかなりの金 をかけても、かつてのように嫁入り道具としてのタンス などの家具類やその中に入れる着物などは、都会などで はむしろ邪魔な存在と考えるような事態さえ現れるよう になった ${ }^{68}$ 。

Le fait est que beaucoup de jeunes couples vivent dans des appartements, que ces derniers sont normalement équipés de placards et que les occasions de porter des kimonos se font rares, car ils ne font plus partie de la vie quotidienne. Beaucoup de jeunes femmes mariées après 1990 - période coïncidant avec la fin de la bulle économique - ont indiqué lors des entretiens, qu'elles préféraient avoir de l'argent pour acheter ce dont elles avaient besoin.

Enfin, il faut aussi tenir compte du fait que l'on estime que c'est le curriculum scolaire (renommée de l'université, diplôme) qui façonne la hiérarchie sociale dans le Japon contemporain industriel ${ }^{69}$. Dans une telle société, les femmes font de plus en plus d'études et cela a une incidence sur la nécessité d'avoir un trousseau. Est-il devenu complètement obsolète pour autant ? Peut-être sous-estimons-nous un peu l'importance des facteurs économiques dans les mariages actuels et ne cherchons-nous pas dot et trousseau au bon endroit.
68. Kuraichi, 1999, p. 116.
69. TACHibanaki, 2008, p. 93. 


\section{CIPANGO \\ 326 Cahiers d'études japonaises $n^{\circ} 23$}

\section{Les études}

Une informatrice de Nagoya (T. C., née en 1932) mariée en 1954 expliquait qu'elle n'avait pas apporté un grand trousseau lors de son emménagement avec son époux dans une maison appartenant aux parents de ce dernier. Elle n'y apporta concrètement qu'une boîte pour ranger les socques et des armoires avec quelques kimonos, mais pas beaucoup. Le peu de splendeur de ses affaires de mariée n'avait cependant aucune importance à ses yeux, car elle possédait quelque chose de plus important : un métier. Bien que ses parents aient eu huit enfants, ils n'ont pas rechigné à sortir l'argent nécessaire à ses études de coiffeuse. C'est une somme qu'ils ont cependant retirée du patrimoine de la maison. Elle ne s'est donc pas sentie lésée lorsqu'ils ne lui ont donné qu'un trousseau réduit et qu'ils ont expliqué à leurs enfants qu'ils voulaient que tous renoncent à leur héritage pour que les terres puissent être transmises à l'aîné des garçons ${ }^{70}$.

L'histoire plus récente d'une informatrice qui était en train d'organiser son mariage au moment de l'enquête de terrain réalisée entre 2005 et 2008 attestait, elle aussi, de ce que les études sont considérées comme une sorte d'avance sur l'héritage équivalente à celle que peut engendrer la constitution d'un trousseau conséquent. Bien que la mère de l'informatrice lui ait donné en secret une petite somme d'argent et que sa grand-mère se soit arrangée pour lui donner des futon, sa famille lui avait annoncé qu'elle ne pensait pas contribuer davantage à ses noces. Lorsque son unique sœur aînée s'était mariée, leur attitude avait cependant été très différente. Ils n'avaient pas hésité à dépenser sans compter. Ses parents ont cependant expliqué à l'informatrice que, contrairement à elle, sa sœur aînée n'était pas allée à l'université. Or, la somme qu'ils ont dépensée pour le mariage de leur fille aînée et celle qu'ils ont investie pour l'éducation de notre informatrice qui est allée à Tōkyō étudier l'archéologie étaient d'un montant approximativement similaire d'après eux :

Lorsque ma sœur s'est mariée, elle avait 18 ans. C'était il y a 14 ans. Mes parents se sont occupés de tout, par exemple d'acheter

70. Ce qui revenait à privilégier un seul héritier comme cela se faisait avant la réforme successorale d'après-guerre pour garder intacte l'ie en indemnisant les autres descendants. 
des meubles et plein de trucs, tout de A à Z. Dans mon cas, ils ne lèvent pas le petit doigt. Ils ne me donnent pas d'argent non plus. Ils nous disent de le [l'achat de ce qui est nécessaire pour la vie conjugale] faire nous-mêmes. Moi, je suis allée à l'université mais ma sœur n'y est pas allée. L'argent utilisé pour ses noces et l'argent utilisé pour que je puisse aller à l'université sont à peu près de la même importance. C'est comme ça.

家のお姉ちゃんは結婚した時十八歳であった。十四年 前だね。例えば家具を買ったりいろいろ買ったりするけ れども何から何まで親が口を出すという。私の場合は何 もしてくれない。お金も出してくれない。自分たちでや りなさいといわれている。私は大学を出ましたが、姉は 大学を出ていない。姉の結婚式に掛かったお金と私を大 学に行かせたお金が同じぐらいですね。そういう風にな っている。

Constitution d'un trousseau et financement de diplômes sont ici placés au même niveau. Dans les deux cas, il s'agit d'avances sur l'héritage familial mais de natures différentes. L'une est cependant plus populaire que l'autre, et les filles sont aujourd'hui aussi nombreuses à faire des études que les garçons.

Depuis la fin de la Seconde Guerre mondiale, le nombre de jeunes qui poursuivent des études supérieures a notoirement augmenté. Si, dans un premier temps, la majorité de ces jeunes était essentiellement des garçons, cela n'est plus le cas. Le nombre de jeunes filles faisant des études supérieures a en effet significativement augmenté à partir des années 1960 selon les chiffres communiqués par le White Paper on Gender Equality ${ }^{71}$. Le même document montre aussi que $56,2 \%$ des jeunes filles ont continué leurs études après le lycée en 2011, un pourcentage très légèrement supérieur à celui des garçons (56\%). On peut alors dire que le financement d'études supérieures pour les filles est

71. DANJO KYōDō SANKAKU-KYOKU, 2012, p. 112. 


\section{CIPANGO \\ 328 Cahiers d'études japonaises $n^{\circ} 23$}

devenu plus important que le fait de leur constituer un trousseau consistant en des armoires et des kimonos.

Les filles font par ailleurs des études de plus en plus longues. Le pourcentage de filles ayant choisi de continuer leurs études dans le supérieur mentionné dans le paragraphe précédent regroupe en réalité deux chiffres : celui des jeunes filles ayant choisi d'aller dans des universités à cycle court (deux ans) et celui des jeunes filles ayant choisi d'aller dans une université à cycle long (quatre ans). Pendant longtemps, la plupart des jeunes filles entrait dans les universités à cycle court. Cela n'est plus le cas depuis le milieu des années 1990. Bien que, en 2011, encore $10,4 \%$ des 56,2\% de jeunes filles ayant décidé de faire des études supérieures aient choisi une université à cycle court (soit une sur cinq environ), la longueur des études des deux sexes tend à se rapprocher.

Comme les parents financent les études de tous leurs enfants et que les formations tendent à devenir de plus en plus identiques, on peut penser que l'héritage est effectivement devenu égalitaire entre les deux sexes et que la notion de dot est devenue totalement caduque. Il n'en reste pas moins que l' investissement académique réalisé par la famille n'a cependant pas nécessairement la même consistance ni le même but selon le sexe des enfants.

\section{Les diplômes ne seraient-ils pas une forme de dot?}

Notons, tout d'abord, qu'il existe encore des différences dans les disciplines choisies selon les sexes. En 2011, ce sont les sciences sociales (26,2 \%) qui prévalaient parmi les étudiantes, suivies par la littérature (23,3\%). Les sciences sociales sont aussi la filière la plus populaire parmi les jeunes hommes (40,1\%). Ils sont cependant peu présents dans la filière littéraire. Ce sont les études en génie $(23,7 \%)$ qui viennent en deuxième position dans leur $\mathrm{cas}^{72}$.

Les carrières professionnelles ne sont pas non plus les mêmes selon le genre. En ce qui concerne l'entrée des jeunes femmes sur le marché du travail, il est indéniable que leur taux d'activité est globalement de plus en plus élevé, même si elles commencent à travailler de plus en plus tardivement. L'activité des femmes

72. Tachibanaki, 2008, p. 93. 
est par ailleurs plus stable tout au long de leur vie : la fameuse courbe en $\mathrm{M}$ qui caractérisait le travail féminin (les femmes arrêtaient de travailler quand elles fondaient une famille et elles ne reprenaient une activité qu'une fois les enfants grands) tend à s'estomper ${ }^{73}$. Malgré ces progrès, l'emploi féminin est cependant encore relativement fragile à plusieurs égards.

En 2011,80,1\% des hommes actifs avaient un emploi à temps complet contre seulement $45,3 \%$ chez les femmes (42,1\% des femmes actives travaillent à temps partiel contre $9,7 \%$ chez les hommes) ${ }^{74}$. La surreprésentation des femmes dans les emplois les plus précaires se retrouve à tous les âges, mais devient plus criante après 25 ans. En 2011, $41 \%$ des jeunes femmes âgées de 25 à 34 ans ne bénéficiaient pas d'un emploi standard alors que seulement $15,2 \%$ de leurs collègues masculins se trouvaient dans cette situation ${ }^{75}$. Ensuite, on remarquera aussi une différence notoire de taux d'activité entre les femmes mariées et celles qui ne le sont pas, les premières travaillant bien moins que les secondes : en 2011 environ $90 \%$ des femmes âgées de 25 à 34 ans non mariées travaillaient contre $55 \%$ chez leurs consœurs mariées ${ }^{76}$. Enfin, la naissance d'un enfant rime encore avec cessation d'activité. Sur la période allant de 2005 à 2013, 62 \% des femmes qui étaient actives lorsqu'elles sont tombées enceintes étaient encore sans emploi un an après la naissance de leur premier enfant ${ }^{77}$. Le constat est sans appel : bien que les filles fassent des études de plus en plus poussées, leurs carrières professionnelles sont bien plus erratiques que celles des garçons, surtout lorsqu'elles fondent une famille.

En réalité, le but des études que l'on fait faire aux filles n'est donc peut-être pas exclusivement de s'insérer et de réussir dans le monde du travail. Les perspectives de mariage ne sont d'ailleurs pas absentes des raisons poussant les jeunes à étudier. Comme l'indique Tachibanaki Toshiaki 橘木俊詔 dans Les Différences entre les femmes, la cinquième raison pour laquelle les jeunes souhaitent faire des études

73. DANJO KYŌDŌ SANKAKU KYOKU, 2012, p. 58.

74. Ibid., p. 71.

75. Ibid., p. 72.

76. Ibid., p. 75.

77. Ibid., p. 81. 


\section{CIPANGO \\ 330 Cahiers d'études japonaises $n^{\circ} 23$}

est qu'ils considèrent cela comme un avantage lorsque l'on cherche un partenaire pour se marier ${ }^{78}$.

Le sexe des personnes interrogées au sujet de leur motivation à faire des études n'est pas clairement indiqué dans le travail de Tachibanaki. Quoiqu'il en soit, l'ouvrage révèle par ailleurs que la formation est évidemment un moyen d'avoir une bonne profession rémunérée en conséquence, mais que ce point est plus important pour les garçons que pour les filles. Malgré l'importance des sentiments dans les mariages actuels, le revenu des hommes est toujours un élément pris en compte dans leur conclusion. Un bon prétendant doit aujourd'hui réunir les trois $\mathrm{C}$, à savoir qu'il doit être communicative, cooperative mais aussi confortable, c'est-à-dire disposer d'une certaine aisance financière ${ }^{79}$. Cette dernière condition est encore importante pour les filles car cela leur permet de s'arrêter de travailler pour se dédier à leur famille sans trop de pression financière.

Les parents se montrent d'ailleurs bien plus regardants en ce qui concerne le curriculum du partenaire dans le cadre du mariage d'une fille que dans celui d'un garçon. Leur désapprobation est la troisième raison invoquée parmi les obstacles au mariage chez les femmes $(17 \%)^{80}$. Pourquoi ? Tachibanaki nous explique qu' ils pensent que leur fille sera éventuellement femme au foyer un jour, ce qui implique qu'elle vivra alors du salaire de son époux. Le niveau du revenu de ce dernier déterminera la vie quotidienne du couple ${ }^{81}$. Or, plus les filles font des études, plus elles augmentent leurs chances de se marier avec une personne ayant un niveau de qualification élevé et donc un avenir prometteur.

Même si les diplômes perdent de leur valeur dans le sens où la progression professionnelle des individus est de plus en plus fonction de leur performance au travail plutôt que de leur palmarès académique lorsqu'ils ne sont pas dans des secteurs très spécialisés ${ }^{82}$, l'homogamie scolaire au sein des couples reste la norme. Les études permettent aux femmes de se marier avec un homme d'un niveau

78. 結婚相手を探す時に有利 (TACHIBANAKI, 2008, p. 76).

79. Ibid., p. 119.

80. Ibid., p. 128-129.

81. Ibid., p. 130.

82. Ibid., p. 97-98. 
identique ou supérieur. En 2005, 44,1 \% des couples avait le même niveau scolaire et, dans 35,1\% des cas, le mari avait un niveau supérieur à celui de son épouse. Une étude plus fine montre toutefois que ces mariages hypergamiques ne le sont que légèrement : rares sont les hommes diplômés d'une université qui se marient avec une femme s'étant arrêtée à la fin du collège. Certes, les études protègent les femmes car elles leur permettent de subvenir à leurs besoins sans avoir à dépendre d'un homme, mais ce n'est pas tout. Les années passées dans l'enseignement supérieur s'avèrent aussi être un moyen de faire un bon mariage leur permettant d'arrêter de travailler si elles le souhaitent.

Ce sont d'ailleurs les femmes les plus qualifiées qui s'arrêtent le plus fréquemment lorsqu'elles ont une famille. Ce sont aussi celles qui reprennent le moins une activité professionnelle une fois l'éducation des enfants terminée. En 2002, 89,6\% des femmes âgées de 20 à 24 ans ayant été dans une université à cycle long et éventuellement dans une école doctorale travaillaient. Ce pourcentage chute à 63,6\% chez les femmes de 30 à 34 ans, puis remonte à 68,9\% entre 40 et 44 ans. Pour la même année, les femmes âgées de 20 à 24 ans diplômées du lycée étaient $73,5 \%$ à travailler. Ce chiffre descend à $55,7 \%$ chez les femmes âgées de 30 à 34 ans, puis augmente et culmine à 73,1\% chez les femmes âgées de 45 à 49 ans.

Pour Tachibanaki, cela est dû au fait que les femmes ayant un niveau d'éducation élevé se marient avec des hommes comme elles, qui gagnent des salaires suffisamment confortables pour qu'elles n'aient pas à travailler. Il évoque par ailleurs la déception qu'elles peuvent éprouver lorsqu'elles envisagent de reprendre une activité professionnelle : ayant perdu leur métier lorsqu'elles se sont arrêtées, elles ne peuvent pas trouver de postes aussi intéressants que ceux qu'elles ont quittés lors de leur retour sur le marché de l'emploi.

Enfin, on peut penser que les études peuvent être synonymes d'excellence intellectuelle et que cela peut aider les jeunes femmes à gagner le respect de l'entourage de leur époux. Même si le savoir de la bru n'est pas utilisé dans le cadre d'une activité professionnelle, on peut le voir comme un moyen de mieux s'acquitter du rôle d'épouse puis de mère en secondant le mari ou en prenant en main l'éducation de la génération suivante de façon plus efficace. Pour finir, l'argent qu'elles auront économisé grâce à leur salaire avant d'arrêter de travailler pourra leur servir d'économies mobilisables pour leurs loisirs. En toute logique, cela améliorera leur vie quotidienne de femme au foyer. 


\section{CIPANGO \\ 332 Cahiers d'études japonaises $n^{\circ} 23$}

\section{Conclusion}

Selon le fonctionnement juridique de la maison (ie), l'essentiel des biens familiaux passait à l'aîné des garçons. On ne se désintéressait pas pour autant du sort des autres enfants. Selon leur sexe, les façons de leur assurer un moyen de subsistance variaient. Les filles étaient normalement destinées au mariage. Il est devenu incongru de ne pas leur donner un trousseau à cette occasion à partir de l'ère Shōwa et il a été démontré que ces biens remplissaient les principales fonctions qu'on connaît à la dot.

En effet, le contenu du trousseau devait s'accorder au rang social de la maison de l'époux et il permettait à la jeune femme d'entrer dans une maison d'un niveau social au moins équivalent au sien. De plus, le trousseau était essentiellement constitué de kimonos qui représentaient une vraie fortune féminine d'étoffe, tandis que les propriétés foncières et l'argent étaient plus rares. Le trousseau était donc aussi un moyen d'indemniser les filles que l'on écartait de l'héritage sans mettre la maison en danger. Enfin, les jeunes épouses gardaient le contrôle de leur trousseau. Elles pouvaient transmettre ce qui en restait, mais les kimonos ne sont pas éternels et les propriétés foncières pouvaient n'être données que pour une génération. Le destinataire final de la dot n'était pas la belle-famille ou la descendance. Elle servait surtout à rendre la vie de la jeune épouse chez son mari plus confortable.

La dot dans les Pyrénées audoises partage de nombreux points avec ce que l'on a observé au Japon, mais l'argent y était beaucoup plus présent. Les sommes que l'on donnait aux filles lors de leur mariage étaient consignées et pouvaient servir au financement de la dot des sœurs de l'époux, c'est-à-dire qu'elles étaient la condition d'autres mariages. L'absence ou la restitution d'une dot pouvait prendre de terribles proportions qui ne semblent pas se rencontrer au Japon. S'il existait bien une dot au Japon, celle-ci n'était pas une condition sine qua non.

La dernière question soulevée par l'article concerne la période contemporaine. Les changements apportés à la Constitution et au Code civil après 1945 ont obligé la société japonaise à traiter les hommes et les femmes de manière égale et à adopter le principe de la dévolution égalitaire de l'héritage. Il serait cependant précipité de conclure à la disparition de la dot. Les jeunes femmes ont d'ailleurs continué à apporter des trousseaux avec elles au moment de leur mariage. Ils ne sont pas devenus obsolètes, mais ont évolué au fur et à mesure du développement économique du pays. 
Il est toutefois indéniable que les biens du trousseau sont considérés comme encombrants de nos jours. Les parents préfèrent investir dans l'éducation des filles. Comme ils financent les études de leurs enfants des deux sexes, on pourrait conclure que la société est parfaitement égalitaire et que la dot est enfin devenue obsolète. L'article propose de considérer que les études que l'on fait faire aux enfants n'ont cependant pas nécessairement le même but selon leur sexe. Pour les filles, il s'agit aussi d'un moyen de conclure un mariage intéressant et de s'assurer un niveau de vie confortable chez leur époux comme le faisaient les dots d'antan. Il nous semble donc que les études des filles doivent être considérées comme un moyen d'émancipation, mais qu'elles peuvent aussi être paradoxalement vues comme une sorte de $\ll$ dot scolaire ${ }^{83} \gg$.

\section{Bibliographie}

Beillevaire Patrick, 1986a, « Le Japon, une société de la maison », in Burguière André, Klapisch-Zuber Christiane, Segalen Martine \& Zonabend Françoise (dir.), Histoire de la famille, tome 2, Armand Colin, Paris, p. 237-340.

Beillevaire Patrick, 1986b, « La famille, instrument et modèle de la nation japonaise », in Burguière André, Klapisch-Zuber Christiane, Segalen Martine \& Zonabend Françoise (dir.), Histoire de la famille, tome 3, Armand Colin, Paris, p. 315-350.

Bourdieu Pierre, 2002, Le Bal des célibataires, Seuil, Paris, 266 p.

DANJo KYŌDŌ SANKAKU-KYOKU 男女共同参画局 [Gender Equality Bureau Cabinet Office], 2006, Danjo kyōdō sankaku hakusho 男女共同参画白書

83. Expression empruntée à François de Singly qui constatait à la fin des années 1980 que plus les femmes étaient diplômées, plus elles avaient de chances d'épouser un homme de valeur socioprofessionnelle supérieure à celle de leur père. SingLY, 2002 [1993], p. 24. 


\section{CIPANGO \\ 334 Cahiers d'études japonaises $n^{\circ} 23$}

[White Paper on Gender Equality], Kokuritsu insatsukyoku 国立印刷局, Tōkyō.

DANJo Kyōdō SANKAKU-KyoKu 男女共同参画局 [Gender Equality Bureau Cabinet Office], 2012, Danjo kyōdō sankaku hakusho 男女共同参画白書, Kokuritsu insatsukyoku 国立印刷局, Tōkyō.

Deliège Robert, 2009 [1996], Anthropologie de la famille et de la parenté, Armand Colin, Paris, 233 p.

Fine Agnès, 1997, « Au fil de la recherche: le trousseau de la mariée », in Bouchard Gérard \& Segalen Martine (dir.), Une Langue, deux cultures: rites et symboles en France et au Québec, Presses de l'université de Laval \& Éditions la Découverte, Laval \& Paris, p. 335-351.

Fine Agnès \& Leduc Claudine, 1998, « La dot, anthropologie et histoire » in Clio-Femmes, dot et patrimoines, no 7, p. 19-50.

FūDosha 風土社, 1987, Aichiken furusato no dentō 愛知県ふるさとの伝統 [Traditions du département d'Aichi pays natal], Aichiken kyōkasho tokuyaku kyōkyūjo 愛知県教科書特約供給所.

Fukuta Ajio 福田アジオ et al. (dir.), 1999, Nihon minzoku daijiten, jō 日本 民俗大辞典 上 [Le grand dictionnaire des coutumes du Japon, tome 1], Yoshikawa Kōbunkan 吉川弘文館, Tōkyō.

Goody Jack, 2001, La Famille en Europe, Éditions du Seuil, Paris, 283 p.

Goody Jack \& Tambiah Stanley Jeyaraja, 1973, Bridewealth and Dowry, Cambridge University Press, Cambridge, 169 p.

HATTORI Makoto 服部誠, 1998, 《Kayoi-kon to nenbutsu bāsan »カヨイ 婚と念仏婆さん [Le mariage 《par visites » et les vieilles qui récitent les invocations au bouddha Amida], in Aichiken-SHi Hensan SENMON IINKAI MinzokU BukAIHEN 愛知県史編さん専門委員会民俗部会編 [Section 
ethnologique du comité spécialisé pour la rédaction de l'histoire du département d'Aichi] (ed.), Aichiken-shi minzoku chōsa hōkoku-sho 1 Shinojima 愛知県史民 俗調査報告書 1 篠島 [Compte-rendu de l'enquête ethnologique et historique du département d'Aichi 1 Shinojima], Aichiken sōmubu 愛知県総務部 [Service des affaires générales du département], Nagoya, pp. 123-155.

HATtori Makoto 服部誠, 2000, «Higashi Mikawa no tsūka girei » 東三 河の通過儀礼 [Rites de passage de l'est de Mikawa], in Aichiken-Shi Hensan Senmon Innai Minzoku Bukainen 愛知県史編さん専門 委員会民俗部会編 [Section ethnologique du comité spécialisé pour la rédaction de l'histoire du département d'Aichi] (ed.), Aichiken-shi minzoku chōsa hōkokusho 3 Tōei Okumikawa 愛知県史民俗調査報告書 3 東栄 奥三 河 [Compte-rendu de l'enquête ethnologique et historique du département d'Aichi 3 Tōei et fond du Mikawa], Aichiken sōmubu 愛知県総務部 [Service des affaires générales du département], Nagoya, pp. 149-179.

HATtori Makoto 服部誠, 2001a, « Yomeiri dōgu »嫁入り道具 (Trousseau), in SHINSHŪ NAgOYASHI-SHI Henshū IINKAI 新修名古屋市史編集委員 会 [Comité pour la nouvelle rédaction de l'histoire de la ville de Nagoya] (ed.), Shinshū Nagoyashi-shi dai-kyükan minzoku-hen 新修名古屋市 第九巻 民俗編 [La nouvelle rédaction de l'histoire de la ville de Nagoya, Tome 9, Ethnologie], Nagoyashi, Nagoya, pp. 517-521.

HATTORI Makoto 服部誠, 2001b, « Owari no Yomeiri »尾張の嫁入り [L'entrée de la bru dans l'Owari], in Aichiken-Shi Hensan SenMon IINKaI Minzoku BuKAIHEN 愛知県史編さん専門委員会民俗部会編 [Section ethnologique du comité spécialisé pour la rédaction de l'histoire du département d'Aichi] (ed.), Shinshū Nagoyashi-shi dai-kyūkan minzoku-hen 新修名古屋市 第九巻 民俗編 [Compte-rendu de l'enquête ethnologique et historique du département d'Aichi 4 Tsushima et ouest de l'Owari], Aichiken sōmubu 愛知 県総務部 [Service des affaires générales du département], Nagoya, pp. 208-235.

Hattori Makoto 服部誠, 2002, « Bitō, bihoku chiiki no tsūka girei » 尾東尾北地域の通過儀礼 [Rites de passage dans les régions du nord et de l'est de l'Owari], in Aichiken-Shi Hensan Senmon Iinkai 


\section{CIPANGO \\ 336 Cahiers d'études japonaises $n^{\circ} 23$}

MINZOKU BUKAIHEN 愛知県史編さん専門委員会民俗部会編 [Section ethnologique du comité spécialisé pour la rédaction de l'histoire du département d'Aichi] (ed.), Aichiken-shi minzoku chōsa hōkokusho 5 Inuyama, Owari Töbu 愛知県史民俗調査報告書 5犬山・尾張東部 [Compterendu de l'enquête ethnologique et historique du département d'Aichi 5 Inuyama et l'est de l'Owari], Aichiken sōmubu 愛知県総務部 [Service des affaires générales du département], Nagoya, pp. 128-157.

HATtori Makoto 服部誠, 2003, «Ubuya to jidori, mushō mairi »ウブヤ と地取り・ムショウ参り [Maison d'accouchement, creusement de la tombe et visite au cimetière], in Aichiken-Shi Hensan Senmon IInkai Minzoku BUKAIHEN 愛知県史編さん専門委員会民俗部会編 [Section ethnologique du comité spécialisé pour la rédaction de l'histoire du département d'Aichi] (ed.), Aichiken-shi minzoku chōsa hōkoku-sho 6 Atsumi, higashi mikawa 愛知県史民俗調査報告 書 6 握美 東三河 [Compte-rendu de l'enquête ethnologique et historique du département d'Aichi 6 Atsumi et est de Mikawa], Aichiken sōmubu 愛知県総務部 [Service des affaires générales du département], Nagoya, pp. 125-164.

HatTori Makoto 服部誠, 2005, «Dai-issetsu, Deai to kekkon 》第一節出会 いと結婚 [Section 1, la rencontre et le mariage], in Aichiken-Shi Hensan IINKAI 愛知県史編さん委員会 [Comité pour la rédaction de l'histoire du département d'Aichi] (ed.), Aichiken-shi Minzoku 3 Mikawa 愛知県史 民 俗 3 三河 [Histoire du département d'Aichi, Ethnologie 3 Mikawa], Aichiken 愛知県 [Département d'Aichi], pp. 552-591.

Hattori Makoto 服部誠, 2008, « Dai-issetsu, Deai to kekkon 》第一節出会 いと結婚 (Section 1, la rencontre et le mariage), in Aichiken-Shi Hensan IINKAI 愛知県史編さん委員会 [Comité pour la rédaction de l'histoire du département d'Aichi] (ed.), Aichiken-shi Minzoku 2 Owari 愛知県史民俗 2 尾張 [Histoire du département d'Aichi, Ethnologie 3 Owari], Aichiken 愛知 県 [Département d'Aichi], pp. 544-573.

HATtori Makoto 服部誠, 2009, « Yomeiri dōgu »嫁入り道具 [Trousseau], in SHINshū NAg Oyashi-SHI SHIRyōHen Henshū IINkaI 新修名古屋市 
史資料編編集委員会 [Comité pour la nouvelle rédaction des documents de l'histoire de la ville de Nagoya] (ed.), Shinshū Nagoyashi-shi shiryōhen minzoku 新修名古屋市史資料編民俗 [La nouvelle rédaction de l'histoire de la ville de Nagoya, Documents, Ethnologie], Nagoyashi, Nagoya, pp. 779-782.

HÉraIl Francine, 1990, «Nara, fonctionnaires et moines à la cour », in Esmein Jean, Macé François, Ninomura Hiroyuki \& Souyri Pierre (dir.), Histoire du Japon, Horvath, Genève, p. 71-79.

Hikaku KaZOKU-SHI GAKKAI 比較家族史学会 [Société, 1996, Jiten - kazoku 事典—家族 [Dictionnaire de la famille], Kōbundō 弘文堂, Tōkyō.

Komatsu Kazuhiko 小松和彦, Kuraishi Atsuko 倉石あつ子 \& MiYata Noboru 宮田登 (dir.), 2000, Jinsei girei jiten 人生儀礼事典 [Dictionnaire des rites de la vie], Shōgakukan 小学館, Tōkyō.

Kondō Kayoko 近藤佳代子, 1991, « Meiji zenki no fūfu zaisan kankei » 明治 前期の夫婦財産関係 [Les relations au patrimoine dans le couple au début de Meiji] in Hikaku kazokushi kenkyū - Josei to zaisan 比較家族史研究— 女性と財産 [Recherche sur l'histoire de la famille comparée : femmes et patrimoine], $n^{\circ} 6$, pp. 65-75.

Konuma Isabelle, 2007, « La "crise familiale" au prisme du droit: réformes juridiques et conflits de normes », in Japon pluriel 7, Éditions Picquier, Arles, p. 391-409.

KURAISHi Atsuko 倉石あつ子, 1999, 《Onna no zaisan 》 女財産 [Les biens des femmes], in Kuraishi Atsuko 倉石あつ子, Asano Hisae 浅野久枝, TADENuma Yasuko 蓼沼康子 \& FuruIE Harumi 古家晴美 (eds.), Onna no me de miru minzokugaku 女の眼でみる民俗学 [L'ethnologie du point de vue des femmes], Kōbunken 高文研, Tōkyō, pp. 116-141.

Le Play Frédéric, 1994, Les Mélouga : une famille pyrénéenne au XIXe siècle, Nathan, Paris, 240 p. 


\section{CIPANGO \\ 338 Cahiers d'études japonaises $n^{\circ} 23$}

LÉVI-STrauss Claude, 2002, Les Structures élémentaires de la parenté, réédition de la deuxième édition, Mouton de Gruyter, Berlin \& New York, 591 p.

MaCÉ François \& MaCÉ Mieko, 2009 [2006], Le Japon d'Edo, les Belles Lettres, Paris, $319 \mathrm{p}$.

SHIнōshō 司法省 [ministère des Affaires, 1976 [1880], Zenkoku minji kanrei ruishu 全国民事慣例類集 [Recueil des coutumes civiles du pays entier], Seishisha 青史社, Tōkyō.

Shimada Yoshihito, 2003, Royaumes peul, islamiques et super-ethniques dans le Nord-Cameroun: Autour de Rey-Bouba, African Kingdoms Collection III, Nagoya University, Nagoya, 199 p.

SIngly François de, 2002 [1993], Sociologie de la famille contemporaine, Colin, Paris, 128 p.

TACHibanaki Toshiaki 橘木俊詔, 2008, Jojo kakusa 女女格差, Tōyō keizai shinpōsha 東洋経済新報社, Tōkyō.

TADEnuma Yasuko 蓼沼康子, 1999, 《Samazama na kon.in 》さまざ まな婚姻 [Mariages divers], in NAKAMURA Hiroko 中村ひろ子, Kuraishi Atsuko 倉石あつ子, Asano Hisae 浅野久枝, TAdenuma Yasuko 萑沼康子, FURUIE Harumi 古家晴美 \& MiYATA Noboru 宮 田登 (eds.), Onna no me de miru minzokugaku 女の眼でみる民俗学 [L'ethnologie du point de vue des femmes], Kōbunken 高文研, pp. 23-52.

Résumé : dans le tome deux de L'Histoire de la famille, Patrick Beillevaire écrivait que « de tout temps la notion de dot proprement dite est demeurée étrangère au système familial japonais ». Pourtant, certaines régions sont réputées pour l'effort financier que représente le mariage d'une fille à cause de ce que les parents devront lui donner. C'est le cas de Nagoya 
et de ses environs où l'on dit que « si tu as trois filles, le faîte du toit tombera ». L'importance de la dot n'aurait-elle pas été sous-estimée ? Cet article se propose de montrer dans quelle mesure on peut parler de dot au Japon et d'en apprécier l'importance à partir de l'analyse d'un travail de terrain réalisé dans le département d'Aichi et de la littérature ethnologique locale. L'article reviendra sur la notion de dot dans l'introduction, puis, dans une première partie, il détaillera la coutume des trousseaux dans la région pour en montrer ensuite l'importance économique en deuxième partie, ainsi que ses nouvelles formes dans un dernier volet.

Mots-clés : famille, femme, mariage, dot, trousseau

Abstract: In the second volume of The History of the Family, Patrick Beillevaire wrote that "the notion of dowry itself has been a stranger to the Japanese family system from time immemorial". However, some regions are famous for the great expense that parents bear when marrying their daughter. That is the case in Nagoya and its surroundings where it is said that "if you have three daughters, the ridge beam of the roof will fall". Has the importance of the dowry thus been underestimated? The aim of this article is to understand to what extent it is possible to speak of dowry in Japan and to evaluate its scale, by analyzing the results of fieldwork conducted in Aichi prefecture as well as documents pertaining to the area. The notion of dowry is presented in the introduction. Secondly, I explain the main features of the custom of the trousseau (a form of dowry) in this area and discuss its economic aspect. Finally, the article considers the possible new forms that dowry might take in present-day Japan.

Keywords: family, women, marriage, dowry, trousseau キーワード：家族、女性、婚姻、持参財産、嫁入り道具 
